\title{
Bowel Care in the Elderly
}

\author{
G.C. Spinzi \\ Department of Gastroenterology, Ospedale Valduce, Como, Italy
}

\author{
Key Words \\ Constipation - Fecal impaction - Fecaloma - Fecal \\ incontinence $\cdot$ Elderly, bowel care
}

\begin{abstract}
Background: Intestinal complaints are a frequent health concern for elderly people and their care providers. Aims: To explore the distinction between constipation and the subjective complaints in elderly people and to review the diagnosis, causes and treatment of constipation, fecal impaction, and fecal incontinence. Methods: Review of studies that give information on prevalence, causes, symptoms, and treatment of bowel problems in the elderly, excluding uncontrolled clinical observations. Results: Self-reported constipation and laxative use increase with age and are more common among women, blacks and people of low socioeconomic level. The patient's pharmacological history is fundamental, because medications are the cause of up to $40 \%$ of chronic constipation, and are often used inappropriately. The results of most laxative trials require cautious interpretation, but fiber and laxatives are more effective than placebo against constipation. Much additional research is needed to determine the most cost-effective method of treating intestinal complaints in the elderly. Conclusions: Bowel problems in older people have a considerable impact on the quality of life and have many contributory causes that are often amenable to treatment and management. Results of therapy can be good, leading to alleviation of suffering and the ability to lead a fuller life.

Copyright $\odot 2007$ S. Karger AG, Basel
\end{abstract}

\section{KARGER}

Fax +4161306 1234

E-Mail karger@karger.ch

www.karger.com (c) 2007 S. Karger AG, Basel

0257-2753/07/0252-0160\$23.50/0

Accessible online at:

www.karger.com/ddi
Elderly people frequently suffer from intestinal complaints, which can have a considerable impact on their quality of life [1]. Constipation is common, with a prevalence ranging from 2 to $28 \%$ in the elderly population [2]. The incidence rises to more than $80 \%$ among residents in homes for the old. Constipation is more common among women, blacks and people of a low socio-economic level.

Intestinal disorders are not only frequent but involve significant morbidity, with a high cost; they are therefore a painful problem calling for prompt care and appropriate therapy [3].

\section{Constipation}

Patients and doctors tend to define constipation differently. A consensus definition, the Rome II criteria, is set out in table 1. Old patients complain mainly of difficulty in defecating, hard feces, and a feeling of incomplete evacuation [4]. Treatment should therefore aim to relieve these symptoms, not necessarily raising the frequency of bowel movements (BM) per week.

We must first of all distinguish between acute and chronic constipation in the elderly patient. If the onset is recent, there may be some abdominal emergency, calling for thorough investigation to reach the correct diagnosis (detailed history, physical examination, rectal exploration, radiology, etc.). Chronic constipation may be primary or secondary. Some causes of secondary constipation are listed in table 2. 
Table 1. Rome II criteria for defining chronic functional constipation in adults [data from 29]

Two or more of the following for at least 12 weeks in the preceding 12 months:

- Straining in more than $25 \%$ of defecations

- Lumpy or hard stools in more than $25 \%$ of defecations

- Sensation of incomplete evacuation in more than $25 \%$ of defecations

- Sensation of anorectal obstruction or blockade in more than $25 \%$ of defecations

- Manual maneuvers to facilitate more than $25 \%$ of defecations

- Fewer than 3 defecations per week

The patient's pharmacological history is fundamental, because medications are the cause of up to $40 \%$ of cases of chronic constipation, and are often used inappropriately [5]. Table 3 lists the main drugs that can cause constipation.

Primary constipation can be classified under three headings: normal transit constipation, the most common form; slow-transit constipation, and anorectal dysfunction. Patients with slow-transit forms often complain of abdominal bloating and infrequent BM [6]; anorectal dysfunction can cause a sensation of incomplete evacuation, or of obstruction, or a need for digital manipulation [7]. The symptoms alone, however, are not enough to distinguish the different subtypes.

\section{Diagnostic Evaluation}

A detailed history and thorough physical examination are the basis for initial evaluation of a patient complaining of constipation. Rectal exploration is essential and should aim to assess the anal tone, presence of any masses, skin condition, rectal prolapse, state of the pelvic floor, and sacral dimple, which may suggest neurological problems.

The AGA consensus guideline recommends: full blood counts, blood glucose, TSH, calcemia, creatininemia, sigmoidoscopy or colonoscopy in patients older than 50 with rectal bleeding or significant weight loss [8]. The utility of abdominal X-rays in the fasted patient is questioned.

Radiopaque markers are the most widely used tool for measuring intestinal transit time, and are inexpensive and reproducible [9]. In patients with defecation disorders the markers localize in the rectal ampulla; in trans-
Table 2. Causes of secondary constipation [data from 12]

Endocrine and metabolic diseases

Diabetes mellitus

Hypercalcemia

Hyperparathyroidism

Hypothyroidism

Uremia

Myopathic conditions

Amyloidosis

Myotonic dystrophy

Scleroderma

Neurologic diseases

Autonomic neuropathy

Cerebrovascular disease

Hirschsprung's disease

Multiple sclerosis

Parkinson's disease

Multiple sclerosis

Spinal cord injury, tumor disease

Psychological conditions

Anxiety

Depression

Somatization

Structural abnormalities

Anal fissures, strictures, hemorrhoids

Colonic strictures

Inflammatory bowel disease

Obstructive colonic mass lesions

Rectal prolapse or rectocele

Other

Irritable bowel syndrome

Pregnancy

Drugs

Table 3. Medications commonly associated with secondary constipation [data from 30]

Antacids containing aluminum or calcium Anticholinergics

Antidepressants

Antihistamines

Calcium channel blockers

Clonidine

Diuretics

Iron

Levodopa

Narcotics

Non-steroidal anti-inflammatory drugs

Opioids

Psychotropics

Sympathomimetics 
port disorders the number and distribution of the markers quantify the extent of the process. Diagnostic investigations should not be overdone in the elderly; sophisticated anorectal function tests are rarely necessary, and most patients respond to conservative therapy. There is no evidence-based data supporting routine use of blood chemistry tests, X-rays or endoscopy in the normal workup for patients with no alarming signs. Transit time, anorectal manometry and a balloon expulsion test show up physiological alterations in selected constipation cases, but no single test gives a full pathophysiological profile [10].

The question of the best diagnostic approach is further complicated by the poor standardization of some tests, and the fact that some patients are not collaborative; most of them will anyway enjoy some relief of symptoms with at least 6 months of medical therapy [8].

Once surgical and medical causes of constipation have been excluded, the focus must be on drugs, which cannot always be stopped. Chronic opioids, for instance, are sometimes unavoidable, so in such cases prophylactic laxatives are preferable. One study found fentanyl caused less constipation than oral morphine [11].

\section{Non-Pharmacological Therapy}

It may be useful for the patient to keep a diary, recording the frequency and consistency of their BM, and straining. Many patients are convinced they should have daily $\mathrm{BM}$ and often small changes in habits can improve their perception of bowel regularity [12].

\section{Bowel Training}

Defecation is to some extent a conditioned reflex. $\mathrm{Pa}-$ tients should be encouraged to try and empty their bowels in the morning, when intestinal motor activity is strongest, or half an hour after meals, to take advantage of the gastrocolic reflex [13].

\section{Fiber}

Dietary fiber increases the bulk of the feces and the frequency of $\mathrm{BM}$, besides shortening mean transit time. In Western countries, fiber intake may range from 5 to $10 \mathrm{~g} /$ day, compared with a recommended daily intake of 20-35 g. Patients should be told to increase their fiber in- take gradually - by about $5 \mathrm{~g} /$ week - so as to avoid gas and bloating, which can sometimes make this approach unacceptable [14]. More gas is produced with insoluble fibers, so soluble fibers like psyllium, ispaghula, or glucomannan are tolerated - and accepted - better.

\section{Fluid Intake}

It is usually believed that adequate fluid intake is important in avoiding constipation, though studies to date have not suggested that drinking more improves the frequency, consistency or facility of BM [15]. There is therefore no real evidence that constipation can be successfully treated by giving the patient more liquids, except in cases of overt dehydration.

\section{Physical Exercise}

Physical activity affects colonic motor function, the change being probably proportional to the intensity of the exercise. Population studies confirm that the incidence of constipation is lower among people with heavier physical activity, but it is not clear whether there is actually a causal relation. Prolonged inactivity, especially in the elderly, may slow colonic transit [16]. Modest physical activity is probably helpful in patients with mild constipation. Other factors, such as cognitive function, medications and diet are all equally important in the elderly.

\section{Pharmacological Treatment}

Tramonte et al. [17], in a systematic review of the literature, found that fiber and laxatives were more effective than placebo against constipation. However, it is still not clear whether any particular group of laxatives is preferable to the others, because controlled randomized trials are still scarce, with limited numbers of patients in each single study, and frequent methodological flaws.

Laxatives can be classified under several headings: bulk laxatives, stool softener or emollient laxatives, osmotics, and stimulants. Bulk laxatives include soluble products such as psyllium, pectin, and guar, and insoluble ones such as cellulose. They are hydrophilic, absorbing water from the intestinal lumen, thus increasing the mass of the feces and making them softer.

Stool softeners include liquid paraffin and the docusates. The docusates lower surface tension so water en- 
ters the bowel more easily. They are well tolerated, but less effective than fiber. They may be useful in patients with anal fissures or hemorrhoids that make defecation painful [12]. Mineral oils such as paraffin are not recommended on account of the risk of aspiration, which could lead to a foreign body reaction in the bronchial tract, and because they bind liposoluble vitamins (A, D, $\mathrm{E}, \mathrm{K})$ in the intestinal lumen, reducing their absorption.

\section{Osmotic Laxatives}

These hyperosmolar agents draw water into the intestinal lumen by osmosis. The most widely used are magnesium hydroxide or citrate, or sodium biphosphate. They are regarded as safe because they have no systemic effects, but can cause electrolyte imbalance, leading to hypokalemia, salt/water retention, and diarrhea. They must be employed with care in patients with cardiovascular failure or chronic renal insufficiency.

The osmotic laxative heading also includes sorbitol, lactulose and polyethylene glycol (PEG). Lactulose is split into short-chain fatty acids by the intestinal flora, but may cause flatulence, worsening the patient's symptoms. PEG is not metabolized by the intestinal flora, so it does not cause bloating, and its high molecular weight means it is poorly absorbed, does not interact with other medications, and does not give rise to tolerance [18]. The combination of PEG with electrolytes can therefore be a useful long-term solution, for instance for constipation in patients with Parkinson's disease, multiple sclerosis, or taking drugs that cause constipation.

Stimulant laxatives - senna or bisacodyl - increase intestinal motility and water secretion into the lumen, boosting peristalsis, but they may cause cramps. Contrary to widespread belief, these laxatives do not harm the colonic autonomic nervous system; they have no carcinogenic effect, do not give rise to tolerance or physical dependence, and are inexpensive.

\section{Prokinetic Compounds}

Metoclopramide is not useful and cisapride, which was widely used in the past though with questionable results, was withdrawn from the USA market in July 2000 on account of reports of cardiac arrhythmias. Colchicine and misprostol, which both speed up intestinal transit, have been approved for this indication by the Food and
Drug Administration (FDA). Tegaserod has been used in cases of irritable bowel with constipation. A recent systematic review [19] found that it raised the number of BM but without significantly relieving abdominal pain and discomfort. Further studies are needed in the elderly population.

Lubiprostone is a bicyclic fat that activates chlorine channels, increasing fluid secretion; it has been approved by the FDA. It reduces straining and softens stool, while also increasing the number of BM. It is well tolerated, with no noteworthy side effects, but further investigations are still needed in the elderly.

Suppositories and enemas (glycerin, bisacodyl, phosphate) still play a major role, especially for patients with difficulty in evacuation.

\section{Toileting and Toilets}

The elderly prefer using the toilet rather than a commode, but want the facilities to be clean, and expect a prompt response when they ask staff for help, so personnel must be motivated and trained to provide the necessary care [20]. We must therefore: (a) ensure dignity and privacy as far as possible; (b) control noise and odors, and (c) provide for assistance if requested.

Toilets must be designed with several points in mind: (a) they must provide support for the upper body, with as little risk as possible of falls; (b) the seats should be padded to prevent decubitus ulcers; (c) they must be stable; (d) there must be enough space for cleansing the perineal area, and (e) they must be easy to maneuver.

\section{Fecal Impaction}

Fecalomas are a frequent complication of constipation in the elderly. More than $40 \%$ of elderly patients in homes in Great Britain suffered from this problem, which paradoxically often manifests with diarrhea. The presence of hard feces, usually in the distal colon, causes pain, abdominal distension, obstruction, mental confusion, urinary incontinence, and stercoraceous ulcers. About $4 \%$ of operations for colonic perforation are for these ulcers, which are often only diagnosed post-mortem, because their clinical presentation is frequently insidious; mortality may even reach $50 \%$ [21].

Hard feces may sometimes build up in the proximal rectum, in which case rectal exploration finds no masses and abdominal X-ray may be useful. 
Physiological tests in patients with fecalomas have not found anorectal dyssynergy, inappropriate contraction of the external anal sphincter or puborectal muscle [14]. These patients have increased rectal compliance and an abnormal sense of fullness in the rectum, which has to be more dilated for them to feel the need to defecate.

The first step is to remove the fecaloma manually. Repeated enemas may be needed if the fecaloma is high in the rectum. Once it has been removed, measures must be taken to prevent it recurring. Glycerin suppositories may be useful, 30 min after meals, or PEG with electrolytes every $2-3$ days [22].

\section{Fecal Incontinence}

This refers to accidental, unintentional loss of liquid or solid stool. The term anal incontinence also covers loss of gas. The prevalence is estimated at $2-7 \%$ in the elderly population, and more than $45 \%$ among those in institutions [23]. These are probably underestimates because so many people are unwilling to report the symptom, which obviously has devastating effects on a person's relations with others, self-esteem and quality of life in general, besides the far-reaching economic repercussions. Questioning must bear this possibility in mind, therefore, in elderly people who only report diarrhea. Extreme urgency differs from incontinence, in that the patient senses the presence of feces in the rectum, but cannot contain them. Urgency is more typical of ulcerative proctitis or colitis and serious diarrheic diseases.

Fecal continence relies on various factors: rectal compliance, anorectal sensation, sphincter function, normal muscle and nerve function in the pelvic floor. Equally important is the consistency and volume of the stool and the patient's mental state, which is essential to convey the need to defecate. Changes in any of these factors can contribute to fecal incontinence [14].

There are numerous causes of incontinence. In the elderly the most likely are diabetic neuropathy, neurological diseases (dementia, stroke, etc.), abnormal rectal compliance because of ischemia, pelvic floor dysfunction, sphincter problems, fecalomas, or proctitis due to anal fissures, with rectal fibrosis.

The diagnostic workup should start with a thorough history, detailed investigation of what medications the patient is taking, and careful rectal exploration. Neurological tests may be useful in many patients to assess their mental state, sacral reflexes and perineal sensation. Sig- moidoscopy or colonoscopy serve to check for inflammation.

Further investigations such as anorectal manometry, defecography, electromyography, pudendal nerve function, or rectal ultrasound, should be restricted to the minority of elderly people in good physical and mental condition; history and careful objective examination are usually enough to form the diagnosis in $85 \%$ of cases [24]. Diarrhea and constipation are independent risk factors for fecal incontinence.

Medical management is based on eliminating food or drugs that cause constipation or diarrhea, and prescribing antidiarrheic medication if no clear cause can be found [25]. Chassagne et al. [26] suggest that eliminating fecalomas is fundamental to improve continence in constipated institutionalized elderly people.

\section{Antidiarrheic Drugs}

The main aim is to correct the consistency because it is easier to control formed stool than liquid feces.

Loperamide. This synthetic opioid has an excellent safety profile; it inhibits peristalsis, lengthens transit time, improves sphincter tone and resting pressure, and reduces urgency, stool volume and the frequency of BM. By increasing the contact time with the mucosa it permits greater absorption of water and electrolytes [27]. The drug does not pass the blood-brain barrier and does not cause dependence. A dose of 2-4 mg loperamide in the morning, and sometimes before meals, reduces the risk of incontinence. The main side effect is, of course, constipation which, however, is tolerated better than incontinence. Loperamide is more effective than diphenoxylate and salicylate of bismuth. It should not be used in patients with diarrhea associated with Clostridium difficile on account of the risk of toxic megacolon.

Diphenoxylate. This opiate also inhibits intestinal motility. It can cross the blood-brain barrier and cause mild euphoria. Excessive use leads to constipation and in cases with intestinal inflammation there is the risk of toxic megacolon.

Amitriptyline. This tricyclic antidepressant, with anticholinergic, serotoninergic and antimuscarinic properties, is employed in patients with idiopathic fecal incontinence. Further study is still needed, especially in the elderly, to confirm whether low-dose amitriptyline lowers anorectal pressure, as suggested by a fairly recent open-label trial [28]. 


\section{Biofeedback}

Regardless of the causes of incontinence, this approach may be useful in motivated patients [14] who can sense the rectal distension caused by a balloon, and voluntarily contract the external anal sphincter. Biofeedback is reportedly useful in $50-70 \%$ of cooperative patients, but to date there are few studies in the elderly.
Bowel care is an indicator of quality of care for elderly people who frequently suffer from intestinal complaints. Much current information is not evidence-based, and comes from observations or studies not conducted with the necessary rigor. The clinical implications of intestinal disorders are so far-reaching that we urgently need more information, in order to provide better treatment.

\section{References}

1 Rockwood TH, Church JM, Fleshman JW, Kane RL, Mavrantonis C, Thorson AG, et al: Fecal incontinence quality of life scale: quality of life instrument for patients with fecal incontinence. Dis Colon Rectum 2000;43: 9-17.

- 2 Stewart WF, Liberman JN, Sandler RS, Woods MS, Stemhagen A, Chee E, et al: Epidemiology of constipation (EPOC) study in the United States: relation of clinical subtypes to sociodemographic features. Am J Gastroenterol 1999;94:3530-3540.

-3 Potter J, Wagg A: Management of bowel problems in older people: an update. Clin Med 2005;5:289-295.

4 Harari D, Gurwitz JH, Avorn J, et al: How do older persons define constipation? Implications for therapeutic management. J Gen Inter Med 1997;12:63-66.

5 Niwata S, Yamada Y, Ikegami N: Prevalence of inappropriate medication using Beers criteria in Japanese long-term care facilities. BMC Geriatr 2006;6:1.

6 Koch A, Voderholzer WA, Klauser AG, Muller-Lissner S: Symptoms in chronic constipation. Dis Colon Rectum 1997;40:902-906.

7 Rao SS, Welcher KD, Leistikow JS: Obstructive defecation: a failure of rectoanal coordination. Am J Gastroenterol 1998;93:10421050.

8 Locke GR III, Pemberton JH, Phillips SF: AGA technical review on constipation. Gastroenterology 2000;119:1766-1778.

$\checkmark 9$ Degen LP, Phillips SF: Variability of gastrointestinal transit in healthy women and men. Gut 1996;39:299-305.

10 Rao SS, Ozturk R, Laine L: Clinical utility of diagnostic tests for constipation in adults: a systematic review. Am J Gastroenterol 2005; 100:1605-1615.

11 Radbruch L, Sabatowski R, Loick G, Kulbe C, Kasper M, Grond S, et al: Constipation and the use of laxatives: a comparison between transdermal fentanyl and oral morphine. Palliat Med 2000;14:111-119.
12 Hsieh C: Treatment of constipation in older adults. Am Fam Physician 2005;72:22772285.

13 Rao SS, Sadeghi P, Beaty J, Kavlock R, Ackerson K: Ambulatory 24-hour colonic manometry in healthy humans. Am J Physiol 2001;280:G629-G639.

14 De Lillo AR, Rose S: Functional bowel disorders in the geriatric patient: constipation, fecal impaction, and fecal incontinence. Am J Gastroenterol 2000;95:901-905.

15 Lindeman RD, Romero LJ, Liang HC, Baumgartner RN, Koehler KM, Garry PJ: Do elderly persons need to be encouraged to drink more fluids? J Gerontol A Biol Sci Med 2000;55:361-365.

16 Liu F, Kondo T, Toda Y: Brief physical inactivity prolongs colonic transit time in elderly active men. Int J Sports Med 1993;14:465467.

17 Tramonte SM, Brand MB, Mulrow CD, Amato MG, O'Keefe ME, Ramirez G: The treatment of chronic constipation in adults. A systematic review. J Gen Intern Med 1997; 12:15-24.

18 DiPalma JA, DeRidder PH, Orlando RC, Kolts BE, Cleveland MB: A randomised, placebo-controlled, multicenter study of the safety and efficacy of a new polyethylene glycol laxative. Am J Gastroenterol 2000;95: 446-450.

19 Evans BW, Clark WK, Moore DJ, Whorwell PJ: Tegaserod for the treatment of irritable bowel syndrome. Cochrane Database Syst Rev 2004;CD003960.

20 Romero Y, Evans JM, Fleming KC, Phillips SF: Constipation and fecal incontinence in the elderly population. Mayo Clin Proc 1996; 71:81-92.
21 Maurer CA, Renzulli P, Mazzucchelli L, Egger B, Seiler CA, Büchler MW: Use of accurate diagnostic criteria may increase the incidence of stercoral perforation of the colon. Dis Colon Rectum 2000;43:991-998.

22 Chen CC, Su MY, Tung SY, Chang FY, Wong JM, Geraint M: Evaluation of PEG + electrolytes in the treatment of severe constipation and faecal impaction in adults. Curr Med Res Opin 2005;21:1595-1602.

23 Dey AN: Characteristics of elderly nursing residents: data from the 1995 National Nursing Home survey. Adv Data 1997;289:1-8.

24 Keating JP, Stewart PJ, Eyers AA, Warner D, Bokey EL: Are special investigations of value in the management of patients with fecal incontinence? Dis Colon Rectum 1997;40: 896-901.

25 Scarlet Y: Medical management of fecal incontinence. Gastroenterology 2004; 126 : S55-S63.

26 Chassagne P, Jego A, Gloc P, Capet C, Trivalle C, Doucet J, Denis P, Bercoff E: Does treatment of constipation improve incontinence in institutionalised elderly patients? Age Ageing 2000;29:159-164.

27 Musial F, Erick P, Kalveram KT, Erckenbrecht JF: The effect of loperamide on anorectal function in normal healthy men. J Clin Gastroenterol 1992;12:321-324.

-28 Santoro GA, Eltan BZ, Pryde A, Bartolo MS: Open study of low-dose amitriptyline in the treatment of patients with idiopathic fecal incontinence. Dis Colon Rectum 2000;43: 1676-1682.

29 Thompson WG, Longstreth GF, Drossman DA, Heaton KW, Irvine EJ, Muller-Lissner SA: Functional bowel disorders and functional abdominal pain. Gut 1999;45:II45.

- 30 Prather CM, Ortiz-Camacho CP: Evaluation and treatment of constipation and fecal impaction in adults. Mayo Clin Proc 1998;73: 882 